\title{
Degree of Deafness in the School for the Deaf in Akure, Ondo State, Nigeria
}

\author{
M. I. Akenroye, and A. Akinbohun
}

\begin{abstract}
The various causes of deafness in children are not uncommon in our environment, despite global efforts on immunization against infectious diseases and other known predisposing factors to this hidden disability. Prevention of deafness must be a priority to all the stake holders. However, the need to know the degree of deafness among those in the school for the deaf so as to know those that can benefit from amplification via the use of high - tech hearing aid or cochlear implant cannot be over-emphasized; hence this study. A prospective study of deaf children in a school for the deaf was carried out over a 7-month period from July 2005 to January 2006 at the ENT Department, Ondo State Specialist Hospital, now University of Medical Sciences Teaching Hospital, Akure. A total of 311 pupils comprising 173 males and 138 females had screening and hearing aid trials. Age range was 7 to 20 years. A total of 64 pupils $(20.6 \%)$ were moderately deaf, 32 pupils $(10.3 \%)$ were severely deaf while 215 pupils $(69.1 \%)$ were profoundly deaf. The use of hearing aids, timely cochlear implantation and other rehabilitation measures could bring the beneficiaries into the mainstream of formal education and improved post - qualification employment opportunities.
\end{abstract}

Index Terms - Deafness, disability, cochlear implant, hearing aids.

\section{INTRODUCTION}

Deafness is a hearing handicap which limits the potential of its sufferer. It has been observed that speech and language skills start to develop early in a child's life. Within months of birth, they begin to hear and recognize the rhythm and melody of speech and often cooing in response to speech [1]. If hearing problems remain unrecognized and as such untreated or recognized late and subsequently partially treated, the development of speech, language and learning skills would be impaired. This late recognition with its attendant little or no treatment is often what obtains in most resourcechallenged countries of the world especially the West African Sub- region [2].

In 2005, it was reported that 1 in 20 Americans were deaf or hard of hearing. Mitchell had estimated 28.8 million Americans as deaf or hard of hearing [3]. In a study in South Africa, 4 million people were reported to be suffering from this hidden handicap [4].

According to the 2001 South African census, approximately 20 percent of all disabled people in South Africa have a hearing loss [4]. As would be expected for a country with South Africa's history, unemployment and illiteracy are high in South Africa's deaf community.

In our country Nigeria, there is no systematic hearing screening programme for children at birth or later in life [4].
This is similar to what obtains in most countries of the Sub Saharan Africa. The problems affecting deaf education in Nigeria include: the negative attitude of many Nigerians towards people with special needs; inadequate funding by the government and other stakeholders; lack of screening, teaching and rehabilitation equipment; shortage of education and medical personnel; late identification of deafness and high illiteracy / poverty levels [5].

The establishment of the School for the Deaf is therefore the only safety valve where most of the significantly hearing impaired can be rehabilitated educationally and skill- wise. The first school for the deaf was established in Nigeria in 1958 - Lagos Wesley School for the Deaf. To meet the growing population of the deaf in Nigeria, the Schools for the Deaf were established in nearly all the 36 states of the federation. Akure School for the Deaf was among the 12 of such schools established between 1976 and 1977 [6].

\section{AIMS AND OBJECTIVES OF THE STUDY}

To identify the students who could be positively assisted back to normal or close to normal life by using hearing aids or recommendation for cochlear implant procedure.

To identify any assistance that can be given collectively to improve their learning ability and quality of life

\section{MEthodolOGY}

\section{A. Study Area/Study Population}

All the pupils in the school for the deaf located in Akure, the Ondo state capital participated in the study. They were conveyed in batches to the State Specialist Hospital, now University of Medical Sciences, Akure for the study.

\section{B. Ethical Approval and Informed Consent}

Ethical approval was obtained from the Ondo state Ministry of Health. Informed consent was obtained from their parents / guardians through the school authority. Every participant had a verbal consent obtained from him or her. It was communicated to them by sign language with the help of their teachers.

\section{Procedure}

The study lasted for 7 months (July 2005 to January 2006). All the pupils were physically examined by the Doctor and necessary attention given to all the pupils with wax or debris in the ears. Those with active ear infections and ear

Published on July 10, 2020.

M. I. Akenroye, Momak Specialist Hospital, Nigeria.

A. Akinbohun, University of Medical Sciences Teaching Hospital, Nigeria.

(corresponding e-mail: akinbohunambrose@yahoo.com). 
discharges received appropriate medications for the treatment of their diseases.

This was followed by Pure Tone Audiometry (PTA) which was done in our sound-proof booth using an audiometer model KLD 21. Air conduction frequencies from $125 \mathrm{~Hz}$ to $8000 \mathrm{~Hz}$ and bone conduction frequencies from $500 \mathrm{~Hz}$ to $4000 \mathrm{~Hz}$ were used. Any of the participants that showed subjective perception of sounds (moderate or severe hearing loss) was subsequently tested with hearing aids.

For the purpose of this screening exercise, the PTA was done by ENT Nurses and the speech therapist who had adequately been trained for the exercise.

\section{RESULT}

There were 311 pupils that participated. This was made up of 173 (55.6) males and 138 (44.4) females. Age range was between 17 and 20 years with a mean age 18.5 years. Figure 1 represents the gender distribution of pupils at Akure School for the deaf. Figure 2 shows cumulative degree of deafness among pupils and Figure 3 presents the degree of deafness based on gender.

\section{A. Degree of Deafness}

- $\quad$ Moderately deaf: 64 (35 males, 29 females).

- $\quad$ Severely deaf: 32 (17 males and 15 females).

- $\quad$ Profoundly deaf: 215 (122 males and 93 females).

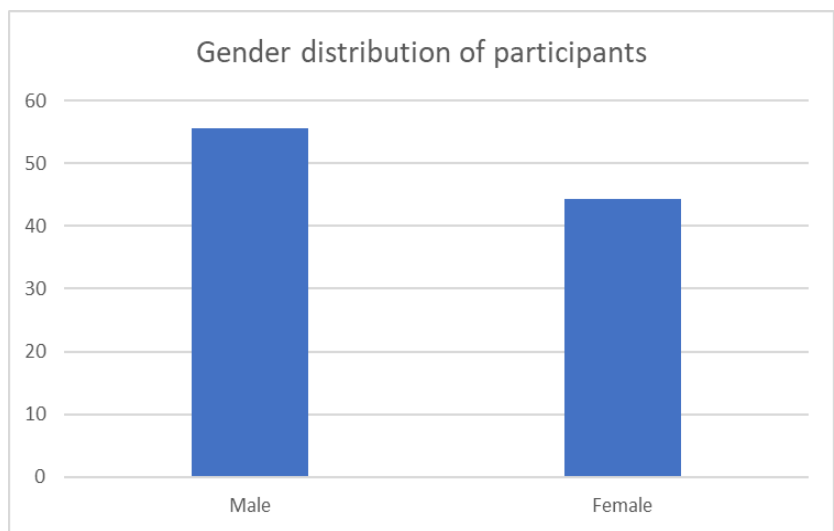

Fig. 1. Gender distribution of pupils at Akure School for the deaf.

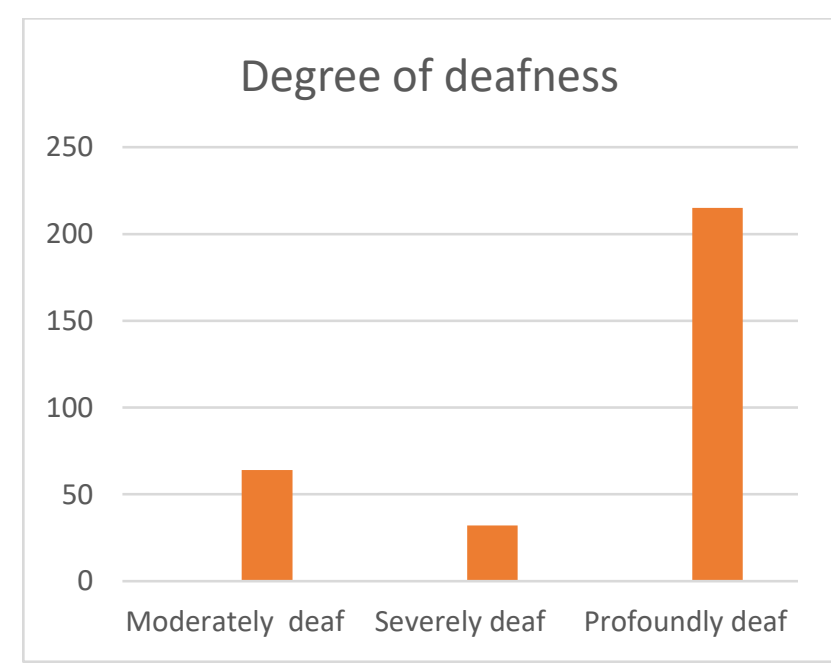

Fig. 2. Cumulative degree of deafness among pupils.

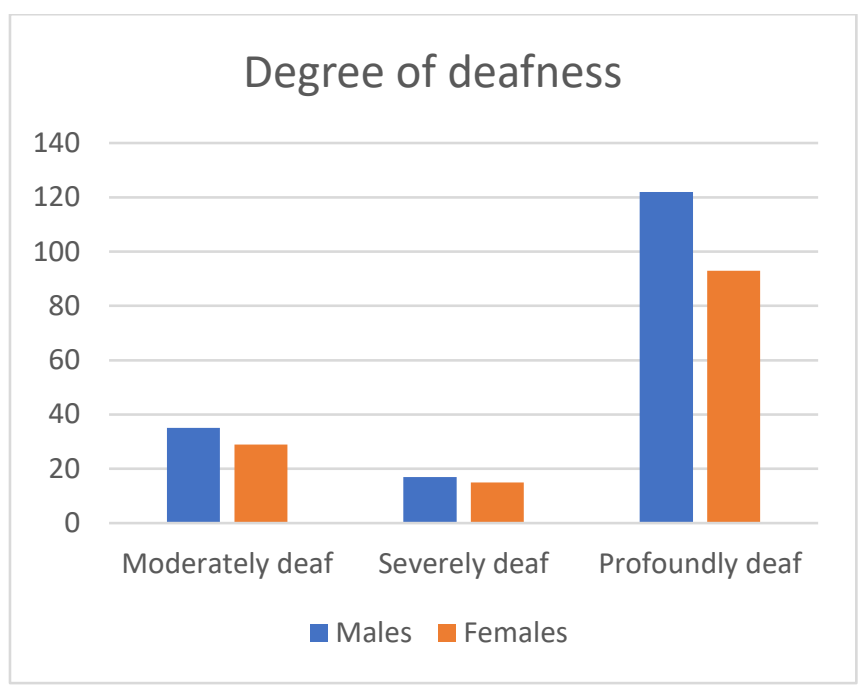

Fig. 3. Degree of deafness based on gender.

\section{DISCUSSION}

There has been an increase in the population of the deaf and hearing impaired globally [4]. Larger percentage of the world's deaf population is expected to be found in SubSaharan Africa where poverty and illiteracy are endemic. In the year 1988, it was reported that there were at least 4 million deaf and hard-of hearing people in South Africa. According to the 2001 South African census, approximately 20 percent of all disabled people in South Africa had hearing loss [1,2]. Causes of deafness could be congenital or acquired. Congenital causes of deafness can either be hereditary or nonhereditary. Hereditary (Genetic) causes can manifest at birth or later in life.

Congenital causes are prematurity, low birth weight, birth injuries, drug and alcohol misuse in pregnancy, maternal diabetes, rhesus factor complications, pre - eclampsia, Down syndrome, Usher's syndrome, Treacher Collins syndrome, Crouzon syndrome, Alport syndrome and Waardenburg syndrome. Common acquired causes include: febrile illness, measles, meningitis, mumps and severe birth asphyxia. In Nigeria, majority of the cases of deafness were seen at preschool age $(<6$ years $)$ [7-11]

Despite spirited efforts at ensuring significant immunization coverage especially among the low-income earners, acquired causes of deafness due to poor participation in the immunization schedules are worrisome.

From Figures 2 and 3, severe and profound deafness were seen in $79 \%$ of the pupils. If such pupils are screened early, appropriate intervention measures can be instituted.

Majority of the pupils with profound hearing loss in our study had been deaf for more than 10 years. The possibility of having a good outcome if such pupils should undergo cochlear implant surgery is uncertain due to neural plasticity. Better outcomes from implant surgeries are expected if operations are done before 2 years of age or at least before 6 years of age $[8,9]$

In our study, there was no history of deliberate hearing intervention measures before being condemned to the school for the deaf.

The simultaneous communication approach is the most common approach used in Nigerian Schools for the Deaf. Spoken English, supported by signs drawn from American 
Sign Language (ASL), as well as special signs developed for use with spoken English are used in schools. If appropriate amplifications and oral language training are added, learning could be enhanced [6]

\section{CONCLUSION}

The clinical evaluation of these students was limited in scope. However, the following submissions can be validly drawn:

None of the students had a hearing loss that is mild; i.e at best a moderate hearing loss in the better ear which is disabling according to WHO standard.

Majority of the students, 69\% (215) were profoundly deaf and did not respond to any sound from both the audiometer and the hearing aid trial.

A total of $96(31 \%)$ of the students responded to sounds from the audiometer and hearing aid. Of this group, 6 students were particularly fascinated by the experience and showed willingness to use the hearing aid.

Majority of the students could not be helped by conventional hearing aids due to their degree of deafness. The few that could be helped, would not achieve maximum benefit except after a protracted training on the hearing aid through the help of a speech therapist.

\section{RECOMMENDATIONS}

The following are the recommendation drawn from the study:

The use of listening devises among those who are moderately deaf may improve their learning ability to catch a better meaning of their lecture materials.

Those with moderate hearing loss who could benefit from hearing aid use could not be assisted immediately due to parental financial constraints. The Government and nongovernmental organizations should come to the aid of such pupils.

Hearing screening for the new born (Neonatal hearing screening programmes) should be instituted in our health policy.

- $\quad$ Repeated screening at regular intervals is advisable for at - risk infants.

Severe and profound degrees of deafness should be subjected to further investigative modalities like Otoacoustic Emission (OAE), Auditory Brainstem Response (ABR) and high-resolution Computerized Tomographic Scan (CT scan) of the inner ear.

More awareness campaigns are recommended for parents to know that they should seek help from appropriate hospitals as soon as they discovered difficulty with hearing in their children. When cases are reported early, treatment and rehabilitation would produce maximum result.

Indiscriminate use of drugs and treatment of children by quarks should be discouraged.

\section{FUNDING}

Mrs. Olufunke Agagu, wife of the former Executive Governor of Ondo State, Nigeria.

\section{CONFLICT OF INTEREST}

None.

\section{ACKNOWLEDGMENT}

We would like to use this opportunity to appreciate Her Excellency Mrs. Olufunke Agagu, wife of the Executive Governor of Ondo State as at the time the research was carried out for her deep love, care and concern for the physically challenged and for all her efforts to make life worth living for the hearing impaired pupils. We also feel highly honoured to have been identified as able hands to carry out this exercise.

\section{REFERENCES}

[1] Swiller J. The unheard: A memoir of Deafness in Africa. Accessed from www.amazon.com/The Unheard on $1 / 5$ / 2012

[2] Berke J. The Deaf. Med J of Therapeutic Africa 2008; 2: 119-121

[3] Mitchell RE. Deaf Americans. J of Deaf Studies and Deaf education 2005; 11: 112-119.

[4] Disability World, June - July 2000: Issue 3.

[5] http://mjota.org. Accessed on $2^{\text {nd }}$ May, 2012

[6] Ajavon PA. An overview of Deaf Education in Nigeria (2006).

[7] Dumade AD, Segun BS, Olajide TG, Ologe FE. Causes of childhood Deafness in Ilorin Nigeria. A paper presented at the $12^{\text {th }}$ Annual Scientific Conference of Otorhinolaryngological Society of Nigeria, 2002.

[8] Ijaduola GTA. The problems of profoundly Deaf Nigerian Child. Post graduate Doctor 1983; 2: 180-184

[9] Ijaduola GTA. The principles of management of Deafness. Nig Med Practioner 1986; 12: 19-25.

[10] Obiako MN. Profound Childhood Deafness in Nigeria: A three-year survey. Ear and Hearing 1987; 8:74-77

[11] Wilson J. Deafness in Developing Countries. Approach to global Program of Prevention. Arch Otolaryngol 1985; 111: 2-9.

M. I. Akenroye is a Chief Consultant in Ear, Nose, Throat, Head and Neck Surgery of University of Medical Science Teaching Hospital, Akure, Nigeria. He possesses special interest in Head and Neck Surgery. $\mathrm{He}$ is a trainer of medical students and Residents (Post Graduate Medical Doctors in Training). He has authored several publications. He is a Chief Examiner at both National Postgraduate Medical College of Nigeria and West African College of Surgeons and a fellow of both Colleges.

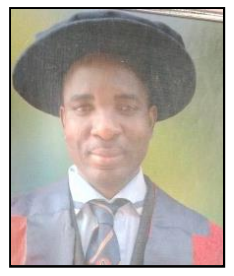

A. Akinbohun is a Principal Consultant in Ear, Nose, Throat, Head and Neck Surgery of University of Medical Science Teaching Hospital, Akure, Nigeria. He possesses special interest in Head and Neck Surgery. He is a trainer of medical students and Residents (Post Graduate Medical Doctors in Training). He is the current Head of Department and has authored a number of publications. He is a public speaker at both radio and television programmes. He is a fellow of the West African College of Surgeons and an examiner of the West African College of Surgeons 